Refinement of primary $\mathrm{Si}$ in hypereutectic Al-Si alloys by intensive melt shearing

This content has been downloaded from IOPscience. Please scroll down to see the full text. 2012 IOP Conf. Ser.: Mater. Sci. Eng. 27012042

(http://iopscience.iop.org/1757-899X/27/1/012042)

View the table of contents for this issue, or go to the journal homepage for more

Download details:

IP Address: 134.83.1.242

This content was downloaded on 29/04/2015 at 15:41

Please note that terms and conditions apply. 


\title{
Refinement of primary Si in hypereutectic Al-Si alloys by intensive melt shearing
}

\author{
Z Zhang, H-T Li, I C Stone and Z Fan \\ EPSRC Centre - LiME, BCAST, Brunel University, Uxbridge, Middlesex, UB8 3PH, \\ UK \\ E-mail: ian.stone@brunel.ac.uk
}

\begin{abstract}
Hypereutectic Al-Si based alloys are gaining popularity for applications where a combination of light weight and high wear resistance is required. The high wear resistance arising from the hard primary Si particles comes at the price of extremely poor machine tool life. To minimize machining problems while exploiting outstanding wear resistance, the primary Si particles must be controlled to a uniform small size and uniform spatial distribution. The current industrial means of refining primary Si chemically by the addition of phosphorous suffers from a number of problems. In the present paper an alternative, physical means of refining primary $\mathrm{Si}$ by intensive shearing of the melt prior to casting is investigated. Al-15wt\%Si alloy has been solidified under varying casting conditions (cooling rate) and the resulting microstructures have been studied using microscopy and quantitative image analysis. Primary Si particles were finer, more compact in shape and more numerous with increasing cooling rate. Intensive melt shearing led to greater refinement and more enhanced nucleation of primary Si than was achieved by adding phosphorous. The mechanism of enhanced nucleation is discussed.
\end{abstract}

\section{Introduction}

Manufacturers are increasingly interested in hypereutectic Al-Si alloys for applications where a combination of light weight and high wear resistance is required such as liner-less engine blocks, pistons and pumps [1].

To meet the strict 'ultra-mild wear regime' operating targets of automotive engine applications and to minimise excessive machine tool wear, the load bearing primary Si phase must be present as fine, well dispersed particles. This refinement is currently achieved by enhanced heterogeneous nucleation on AlP particles that result from the addition of $\sim 50 \mathrm{ppm}$ phosphorous to the alloy before casting. However the use of $\mathrm{P}$ presents a number of potential problems:

- With prolonged contact time AlP particles agglomerate, float to the melt surface and become incorporated in the dross. This is exacerbated by the agitation due to fluxing and degassing treatments. P must therefore be added after such treatments, potentially leading to reintroduction of hydrogen and deleterious oxide films.

- $\quad \mathrm{P}$ is most effectively added in the form of $\mathrm{Cu}-\mathrm{P}, \mathrm{Al}-\mathrm{Cu}-\mathrm{P}$ or Al-Fe-P master alloys, possibly leading to incorporation of impurities.

- Refinement of primary Si with P is not compatible with the common practice of modification of eutectic Si with Sr or Na. 
Research on binary hypereutectic Al-Si alloys has shown that additions of rare earth elements are a potential chemical alternative to refinement of primary Si with $\mathrm{P}$, and indeed may have the advantage of producing modified Al-Si eutectic simultaneously [2,3]. However the refinement of primary Si appears to be only moderate. Furthermore it is not clear that the refinement evident in binary alloys will translate to commercial multi-component alloys. For instance a group at Shanghai Jiaotong University found that the addition of $\mathrm{La}$ to $\mathrm{Al}-17 \mathrm{wt} \% \mathrm{Si}$ and $\mathrm{Al}-25 \mathrm{wt} \% \mathrm{Si}$ resulted in both refinement of primary Si and eutectic modification [3] whereas similar addition to A390 alloy resulted in neither [4].

Physical approaches to the refinement of primary $\mathrm{Si}$, including ultrasound [5,6], electromagnetic stirring [7] and electromagnetic vibration [8] have been attempted with limited success. Treatments are localised within the melt and take of the order of ten minutes even within very small quantities of liquid.

Over the past decade BCAST at Brunel University has developed the Melt Conditioning by Advanced Shearing Technology (MCAST) in which a liquid alloy is subject to very high shear and intense turbulence within a pair of corotating, fully intermeshing screws [9]. It has been shown that application of MCAST prior to casting can lead to uniform refinement of solid solution grain structures [10] and primary intermetallic phases [11]. The research described in this paper investigates the potential for primary Si refinement in hypereutectic Al-Si alloys using MCAST.

\section{Experimental}

Batches of $\mathrm{Al}-15 \mathrm{wt} \% \mathrm{Si}$ alloy were produced by melting together commercial purity $\mathrm{Al}$ and $\mathrm{Al}-50 \mathrm{wt} \% \mathrm{Si}$ master alloy at $800{ }^{\circ} \mathrm{C}$ in a clay-bonded graphite crucible in an electric resistance furnace. The alloy was cooled to a pouring temperature of $640{ }^{\circ} \mathrm{C}$ prior to casting using each of three techniques to achieve cooling rates over a range of three orders of magnitude: (i) using the Aluminium Association TP-1 test mould (TP-1), (ii) into the $13 \mathrm{~mm}$ diameter cavity of a graphite mould (GR) and (iii) by cold chamber high pressure diecasting (HPDC), with cooling rates of $\sim 3.5 \mathrm{Ks}^{-1}, \sim 10 \mathrm{Ks}^{-1}$ and $>100 \mathrm{Ks}^{-1}$ respectively. HPDC was carried out in a $280 \mathrm{t}$ clamping force machine (LK Machinery Co. Ltd., Hong Kong) to produce samples of the form of round tensile test bars with a gauge diameter of $6.5 \mathrm{~mm}$.

Samples were cast with and without the application of intensive shear to the melt prior to casting. The high shear was achieved using the twin-screw MCAST device. The shear process was carried out at $640{ }^{\circ} \mathrm{C}$ at a speed of $500 \mathrm{rpm}$ (equivalent to a shear rate of approx. $530 \mathrm{~s}^{-1}$ ) for $60 \mathrm{~s}$.

Both sets of experiments were repeated with the addition of $50 \mathrm{ppm} P$ to the melt to (i) allow a comparison between the chemical refinement process with $\mathrm{P}$ and the physical refinement process of melt shearing, and (ii) assess the combined effect of melt shearing and P.

Specimens for microstructural characterisation were sectioned and polished using standard techniques and were observed using a Zeiss Axioskop 2MAT light microscope and using Zeiss Axiovision quantitative image analysis software. The size, shape, number density and volume fraction of primary Si particles were quantified. Primary Si particle size was measured as an equivalent circular diameter. As the primary Si particles were reasonably well dispersed throughout the cross section of the samples, it was reasonable to assume that the volume fraction of primary Si was equal to the area fraction measured from the 2-dimensional section in microscope. The shape of the primary Si particles was quantified in terms of a shape factor, $S=4 \pi A / P^{2}$, where $A$ and $P$ are the area and perimeter of each particle on the plane of the polished surface respectively. $S$ has a value of one for perfectly round particles, and decreases as the particles become more irregular in shape.

\section{Results}

Figure 1 shows the micorstructures of Al-15wt\%Si TP-1, GR and HPDC samples cast without intensive melt shearing, with intensive melt shearing, and with the addition of $50 \mathrm{ppm} \mathrm{P}$ (unsheared). The primary $\mathrm{Si}$ in the Al-15wt\%Si TP-1 sample without shearing (figure 1(a)) was course and irregular. As the cooling rate increased (figures 1(d) for GR \& 1(g) for HPDC) the primary Si particles 


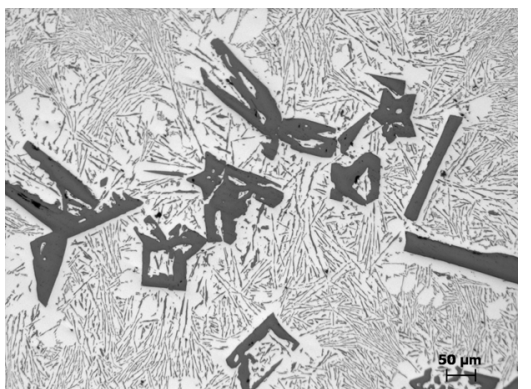

(a)

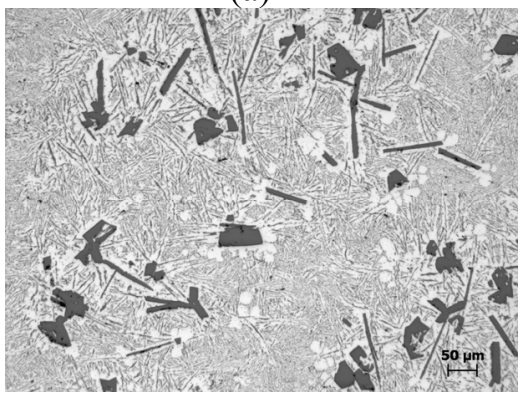

(d)

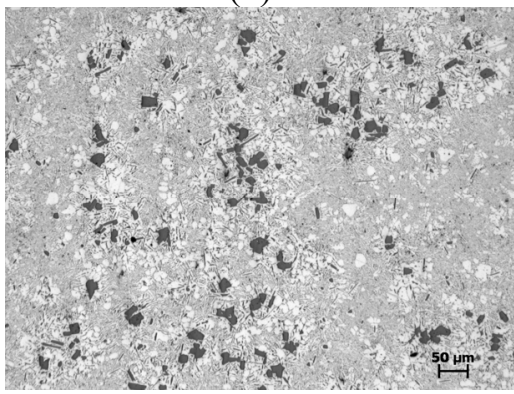

(g)

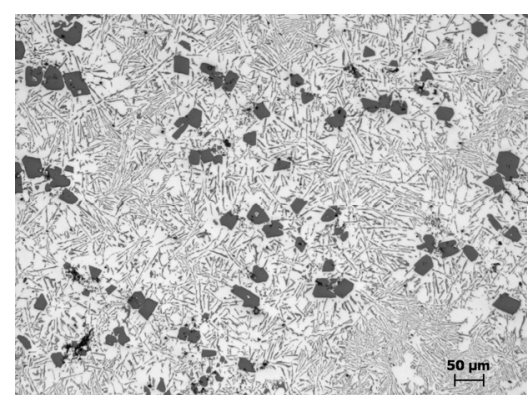

(b)

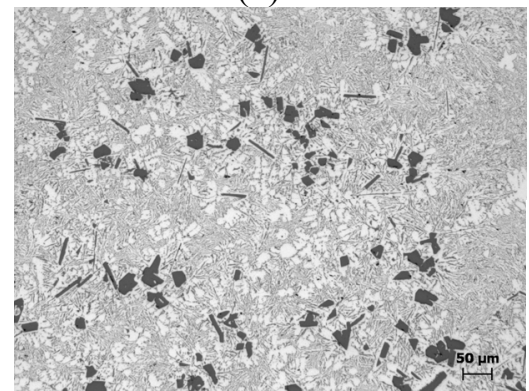

(e)

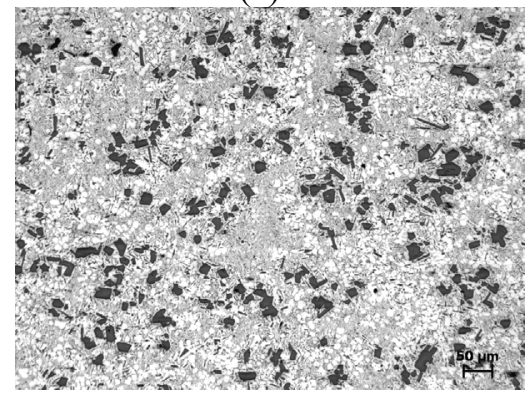

(h)

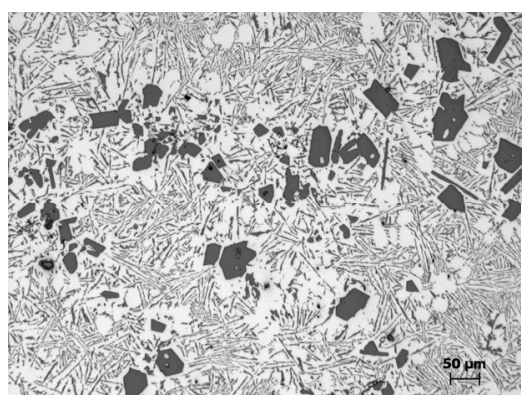

(c)

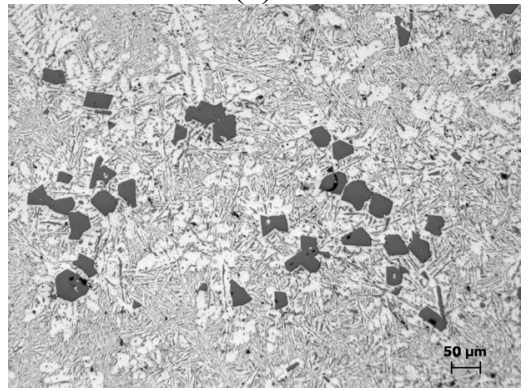

(f)

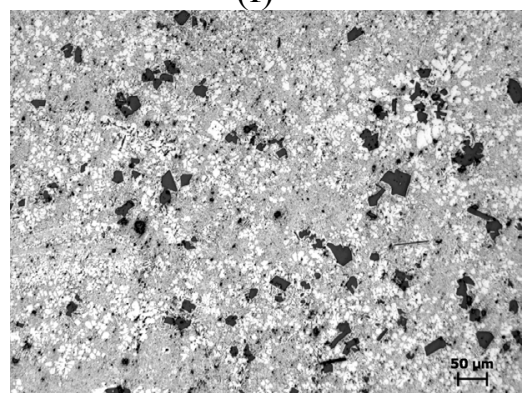

(i)

Figure 1. Light micrographs of $\mathrm{Al}-15 \mathrm{wt} \% \mathrm{Si}$ cast without $(\mathrm{a}, \mathrm{d}, \mathrm{g})$ and with $(\mathrm{b}, \mathrm{e}, \mathrm{h})$ intensive melt shearing, and Al-15wt\%Si with 50 ppm P added (c,f,i): (a-c) TP-1, (d-f) GR and (g-i) HPDC.

became more compact and refined. It is clear from figure 1 that the application of melt shearing led to more compact and refined primary Si. The effect of melt shearing was very significant in the TP-1 samples (compare figure 1(b) with figure 1(a)), and less significant but still apparent in the GR samples (compare figure 1(e) with figure 1(d)). It is difficult to discern from the light micrographs of figures $1(\mathrm{~g})$ and $(\mathrm{h})$ whether melt shearing had any effect on the size of primary Si particles. It could also be observed that the eutectic was also refined with increasing cooling rate and by the application of melt shearing.

Figure 1(c),(f)\&(i) show the microstructures of TP-1, GR and HPDC samples of Al-15wt\%Si with $50 \mathrm{ppm} \mathrm{P}$ added, cast without intensive melt shearing, i.e. the conventional primary Si refinement process. As expected, the addition of P led to refined primary Si with a compact morphology (compare figure 1(c),(f)\&(i) with figure 1(a),(d)\&(g)), with the degree of refinement becoming less significant with increasing cooling rate. The primary Si of the samples cast with intensive melt shearing was refined at least as well as that cast with the conventional $\mathrm{P}$ addition (compare figure $1(\mathrm{~b}),(\mathrm{e}) \&(\mathrm{~h})$ with figure 1(c),(f)\&(i)). When the alloy was cast with both the addition of $\mathrm{P}$ and intensive melt shearing, little further refinement was observed (micrographs not shown).

Figure 2 shows the results of quantitative image analysis of polished sections of TP-1, GR and HPDC samples of Al- $15 \mathrm{wt} \% \mathrm{Si}$ with and without added $\mathrm{P}$, each cast with and without intensive melt shearing using MCAST. Figure 2(a) confirms that the primary Si particle size decreased with 
no P, Unsheared $\square$ With $P$, Unsheared $\square$ No P, Sheared $\square$ With $P$, Sheared

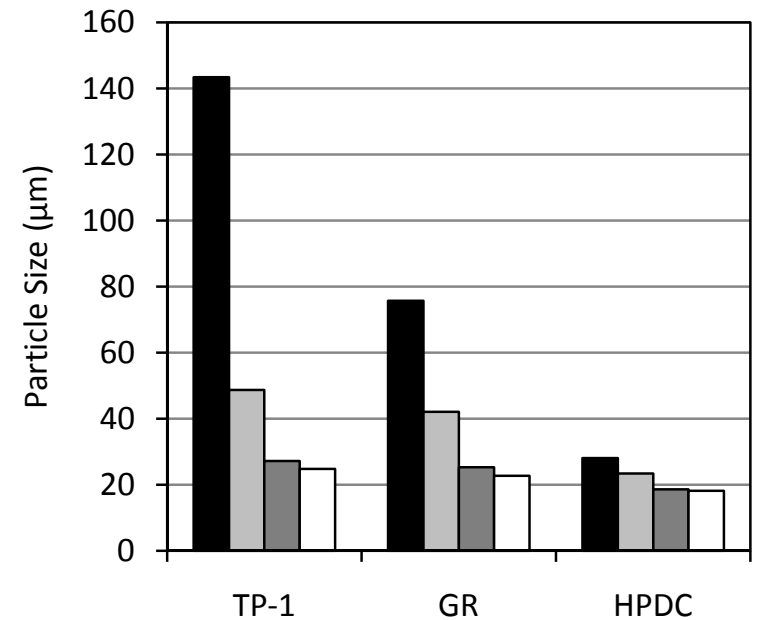

(a)

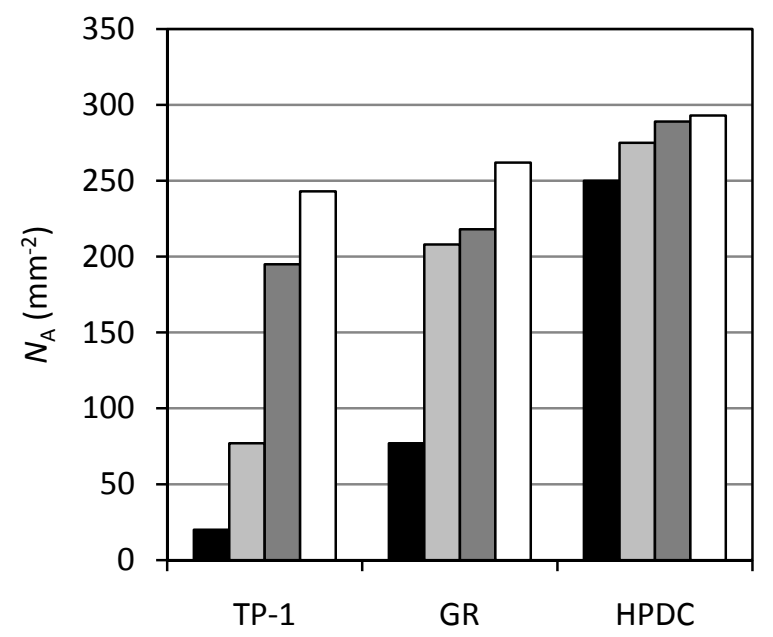

(c)

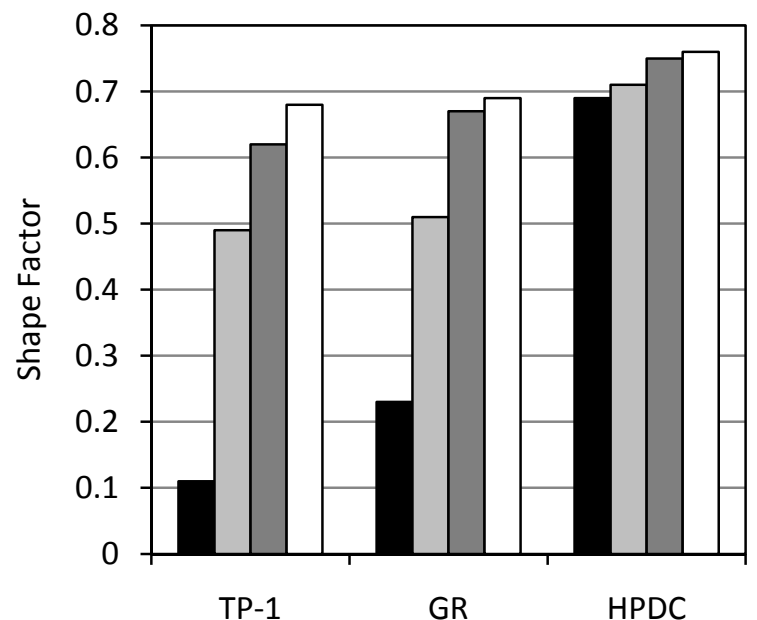

(b)

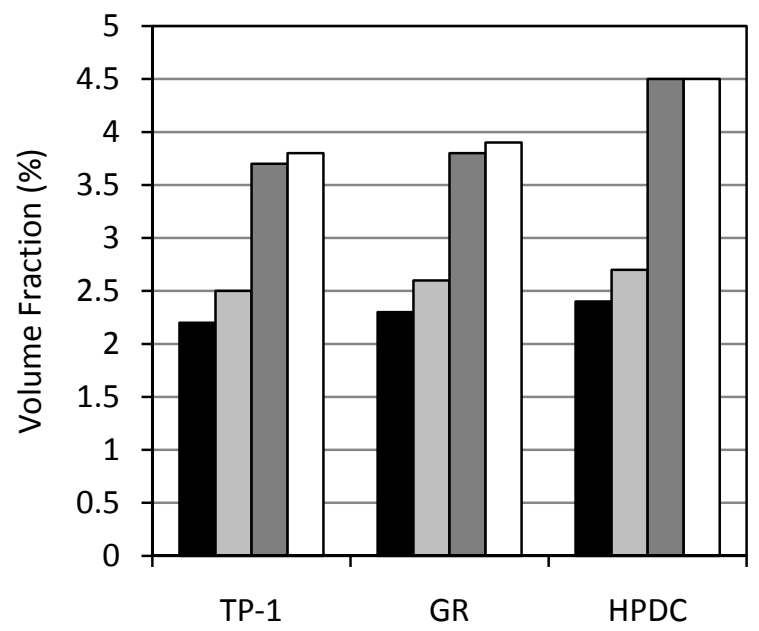

(d)

Figure 2. Results of quantitative image analysis of primary $\mathrm{Si}$ in cast $\mathrm{Al}-15 \mathrm{wt} \% \mathrm{Si}$ : (a) particle size, (b) shape factor, (c) number density $N_{\mathrm{A}}$ and (d) volume fraction.

increasing cooling rate irrespective of whether the melt was sheared prior to casting or whether $\mathrm{P}$ was added. For each cooling rate: (i) the primary $\mathrm{Si}$ was coarsest in the unsheared alloy without $\mathrm{P}$, (ii) adding $\mathrm{P}$ led to refinement of the primary $\mathrm{Si}$, (iii) melt shearing led to greater refinement of primary $\mathrm{Si}$ than the conventional process of adding $\mathrm{P}$ without shearing, and (iv) adding $\mathrm{P}$ in addition to melt shearing provided only marginal further refinement.

Figure 2(b) shows how the shape of the primary Si particles varied with cooling rate and melt treatment. The shape factor increased, i.e. the particles became more compact, with increasing cooling rate. For each cooling rate: (i) the primary Si was most irregular in shape in the unsheared alloy without $\mathrm{P}$, (ii) the shape factor increased with the addition of $\mathrm{P}$, (iii) melt shearing led to more compact particles than the conventional process of adding $\mathrm{P}$ without shearing, and (iv) adding $\mathrm{P}$ in addition to melt shearing provided only a marginal further increase in shape factor. 
Figure 2(c) shows that the number density, $N_{\mathrm{A}}$, of primary Si particles increased with increasing cooling rate. For each cooling rate: (i) $N_{\mathrm{A}}$ was lowest in the unsheared alloy without $\mathrm{P}$, (ii) $N_{\mathrm{A}}$ increased with the addition of $\mathrm{P}$, (iii) melt shearing led to a higher value of $N_{\mathrm{A}}$ than the conventional process of adding $\mathrm{P}$ without shearing, and (iv) adding $\mathrm{P}$ in addition to melt shearing provided only a small further increase in $N_{\mathrm{A}}$.

Figure 2(d) shows the variation in volume fraction of primary Si with cooling rate and melt treatment. The volume fraction of primary $\mathrm{Si}$ increased slightly with increasing cooling rate, e.g. from $2.2 \%$ in the TP- 1 sample to $2.4 \%$ in the HPDC sample for the unsheared alloy without P. The addition of $\mathrm{P}$ led to a marginal increase in volume fraction of primary $\mathrm{Si}$, e.g. from $2.2 \%$ to $2.5 \%$ in the $\mathrm{TP}-1$ samples. However the application of melt shearing resulted in a significantly greater volume fraction of primary $\mathrm{Si}$, e.g. from $2.2 \%$ to $3.7 \%$ in the TP-1 samples and from $2.4 \%$ to $4.5 \%$ in the HPDC samples.

\section{Discussion}

The results in figures $1 \& 2$ show that with increased cooling rate the primary $\mathrm{Si}$ in cast $\mathrm{Al}-15 \mathrm{wt} \% \mathrm{Si}$ becomes more compact and more refined. This finding is not surprising and echoes those of a number of previous investigations [12-15]. Indeed it is noted that cooling rate alone can be sufficient for primary Si refinement in high pressure diecasting although in practice $\mathrm{P}$ additions are frequently used for complete control (if the melt temperature is insufficiently high, the melt dwells for too long in the shot sleeve and/or the flow prior to die filling is too slow then coarse primary Si may form before the melt enters the die cavity) [1].

Figures $1 \& 2$ also show that primary $\mathrm{Si}$ is finer and more compact when the melt undergoes intensive melt shearing than when the conventional process of adding $50 \mathrm{ppm} \mathrm{P}$ is used. In addition, and importantly, the number density of primary Si particles is greater with melt shearing than on the addition of $\mathrm{P}$. The value of $N_{\mathrm{A}}$ is a reflection of the ease with which nucleation takes place. It can be concluded then that intensive melt shearing leads to enhanced nucleation of primary Si compared with conventional P refinement.

It has been shown that intensive shearing in the MCAST unit disrupts oxide films included in the melt and distributes them as well dispersed sub-micron scale oxide particles [9]. Furthermore it has been shown that these dispersed oxide particles act as efficient heterogeneous nucleants for a number of phases including $\mathrm{Al}$ and $\mathrm{Mg}$ solid solutions and primary intermetallic particles [10,11]. Figure 3 shows the microstructure of a region containing an entrained oxide film in a sample produced in the present work. It shows that primary Si particles form in close association with such entrained oxides. Similar association between Si particles and oxide films has been observed by Campbell $[16,17]$. Enhanced formation of Si particles also occurs at folds or laps in castings, e.g. figure 18 in [1]. Such folds inevitably have oxide at their surfaces and hence the fold acts as an oxide bifilm and hence the enhanced formation of $\mathrm{Si}$ at folds provides further evidence of the association of primary $\mathrm{Si}$ with entrained oxide.

A combination of (i) a significant increase in number density of primary Si particles with the application of intensive melt shearing, (ii) past evidence that MCAST leads to distribution of oxide films as well dispersed discrete particles, and (iii) the observed association of enhanced Si formation on oxide, leads to the conclusion that intensive melt shearing causes enhanced nucleation of primary $\mathrm{Si}$ on well dispersed oxide particles. Although this conclusion has yet to be confirmed by direct observation of primary $\mathrm{Si} /$ oxide interfaces, epitaxial growth of oxides on $\mathrm{Si}$ in the semiconductor industry provides support. For instance $\Upsilon-\mathrm{Al}_{2} \mathrm{O}_{3}$ grows on $\mathrm{Si}$ with an orientation relationship of the form $\mathrm{Si}(111) / / \mathrm{Al}_{2} \mathrm{O}_{3}(222), \mathrm{Si}[220] / / \mathrm{Al}_{2} \mathrm{O}_{3}$ [440] [18]. The lattice mismatch over a single unit cell is $>30 \%$, but the mismatch decreases to $2-3 \%$ for the matching of two $\Upsilon-\mathrm{Al}_{2} \mathrm{O}_{3}$ cells to three $\mathrm{Si}$ cells [18]. Similarly $\mathrm{Mg}_{2} \mathrm{Al}_{2} \mathrm{O}_{4}$, which is also the predominant oxide in $\mathrm{Mg}$ bearing $\mathrm{Al}$ alloys, grows on $\mathrm{Si}$ with the a-axes of the two unit cells parallel, and again three lattice spacings of Si match with two lattice spacings of the oxide to within $1 \%$ [19]. 


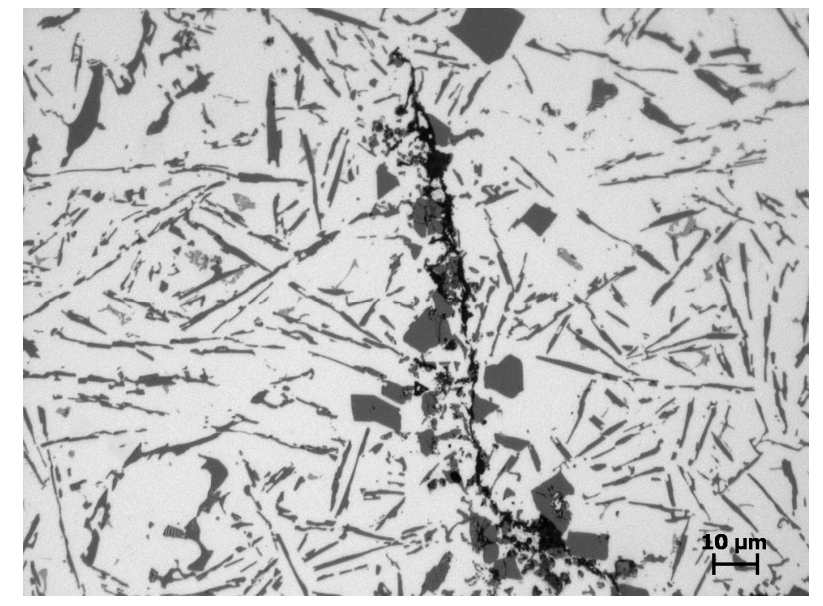

Figure 3. Evidence of the association of primary Si with oxide films.

\section{Conclusions}

An Al-15wt\%Si alloy has been cast at a number of cooling rates, with and without an addition of 50 ppm P, and with and without the application of intensive melt shearing prior to solidification: (i) Intensive melt shearing led to greater refinement of the primary Si particles than the common practice of refining with P; (ii) Intensive melt shearing resulted in a greater number density of primary $\mathrm{Si}$ particles than that achieved by adding $\mathrm{P}$, suggesting that melt shearing provides a means of enhanced nucleation; (iii) This enhanced nucleation is likely to be due to the distribution of oxide films as well dispersed, discrete, nanoscale oxide particles which act as potent/efficient heterogeneous substrates.

\section{Acknowledgements}

The support of EPSRC (grant EP/H026177/1) is gratefully acknowledged.

\section{References}

[1] Jorstad J and Apelian D 2009 Int. J. Metalcasting Summer 13-36

[2] Chang J, Moon I and Choi C 1998 J. Mater. Sci. 33 5015-23

[3] Hongkun Yi and Di Zhang 2003 Mater. Lett. 57 2523-9

[4] Hongkun Yi, Di Zhang, T. Sakata and H. Mori 2003 J. Alloy. Compd. 354 159-64

[5] Youn J I, Kang B I, Ko D G and Kim Y J 2008 Int. J. Cast Metal. Res. 21 135-8

[6] Feng H K, Yu S R, Li Y L and Gong L Y 2008 J. Mater. Process. Tech. 208 330-5

[7] Dehong Lu, Yehua Jiang, Guisheng Guan, Rongfeng Zhou, Zhenhua Li and Rong Zhou $2007 \mathrm{~J}$. Mater. Process. Tech. 189 13-8

[8] Anuradee T, Mawin S, Umeda T, Nagaumi H, Qin K and Cui J Z 2008 Int. J. Cast Metal. Res. 21 198-202

[9] Fan Z and Liu G 2005 Acta Mater. 53 4345-57

[10] Fan Z, Wang Y, Xia M and Arumuganathar S 2009 Acta Mater. 57 4891-901

[11] Wang Y, Xia M, Fan Z, Zhou X and Thompson G E 2010 Intermetallics 18 1683-9

[12] Peijie Li, Nikitin V I, Kandalova E G and Nikitin K V 2002 Mat. Sci. Eng. A 332 371-4

[13] Xu C L and Jiang QC 2006 Mat. Sci. Eng. A 437 451-5

[14] Yamagata H, Kasprzak W, Aniolek M, Kurita H and Sokolowski J H 2008 J. Mater. Process. Tech. 203 333-41

[15] Faraji M, Todd I and Jones H 2005 J. Mater. Sci. 40 6363-5

[16] Cao X and Campbell J 2003 Metall. Mater. Trans. A 34 1409-20

[17] Campbell J 2006 Metall. Mater. Trans. B 37 857-63

[18] Wu S Y, Hong M, Kortan A R, Kwo J, Mannaerts J P, Lee W C and Huang Y L 2005 Appl. Phys. Lett. 87 091908-1-3

[19] Reiner J W, Kolpak A M, Segal Y, Garrity K F, Ismail-Beigi S, Ahn C H and Walker F J 2010 Adv. Mater. 22 2919-38 